International Journal of Linguistics, Literature and Translation

ISSN: 2617-0299 (Online); ISSN: 2708-0099 (Print)

DOI: $10.32996 /$ ijllt

Journal Homepage: www.al-kindipublisher.com/index.php/ijllt

\title{
A Study of Du Fu's Poetry in the West in Modern Times
}

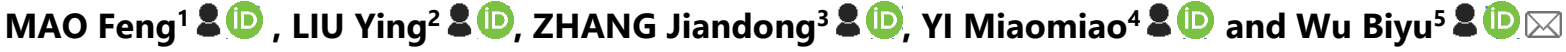 \\ ${ }^{1}$ Associate Professor of School of Foreign Languages, Shanghai University of International Business and Economics, Shanghai, China \\ ${ }^{234}$ Master student of School of Foreign Languages, Shanghai University of International Business and Economics, Shanghai, China \\ ${ }^{5}$ Professor of School of Foreign Languages, East China University of Science and Technology, Shanghai, China
}

$\triangle$ Corresponding Author: Wu Biyu, E-mail: maofeng@suibe.edu.cn

ARTICLE INFORMATION ABSTRACT

Received: May 14, 2021

Accepted: June 20, 2021

Volume: 4

Issue: 6

DOI: 10.32996/ijllt.2021.4.6.15

\section{KEYWORDS}

Du Fu's study, English Translation of Du Fu's Poetry, Dissemination and Acceptance, Visualization Analysis
Chinese classical literature has attracted much attention in the Western world. As an important part of Chinese classical literature, Du Fu's poetry, also as an important carrier, plays a great role in the international communication of cultural confidence. In recent years, some domestic research institutions and scholars have also written literature reviews on the research progress of $\mathrm{Du} \mathrm{Fu}$, but few works of literature comprehensively review related western research results. With the combination of big data and visualization tools, this study uses the title keyword "Du Fu Poetry" to search the English literature of Google scholar. VOSviewer is used to make visual analysis and draw a knowledge map from the aspects of literature quantity, authors, research institutions, co-citation, keyword clustering, etc., to analyze the research situation and hotspots of the Western study of Du's poetry. The following conclusions are drawn: 1) In recent decades, western translation of Du Fu's poetry have emerged constantly, attracting more and more famous international publishing houses to cooperate; 2) The study of Du's poetry abroad mainly focuses on the English translation of Du's poetry as well as the interpretation and evaluation of poets' thoughts; 3 ) The study of Du's poetry abroad ignores the dynamic study of Du's poetry development, and there are some obvious cultural errors or omissions in translation. In a word, this study objectively reflects the development, theme and hotspots of modern western Du Fu poetry research, which has certain significance for fully understanding the general situation of Du Fu research field in Western countries and help to deepen Du Fu's research.

\section{Introduction}

Du Fu is one of the greatest poets in our country. Both the art of poetry and the realm of thought have reached a very high level, and the influence on later generations is also immeasurable. The research about him has been going on for generations, and up to now, there is still a wealth of research finding. With the increasing exchanges between China and foreign countries, more and more attention has been paid to the study of Du Fu in foreign countries. Du Fu poetry, as an important carrier, plays an important role in the dissemination of cultural confidence. In April 2020, BBC released its latest documentary, Du Fu: China's Greatest Poet, in which it compares Du Fu with Dante and Shakespeare, introducing and interpreting Du Fu in their eyes to the world and giving the world a new understanding of Du Fu and his poems.

In order to grasp the achievements and trends of Du Fu-related research, this study first reviews the relevant literature of domestic research institutions and scholars in the past 40 years. With the title of "Du Fu" or "Du Shi" and "Review", this study searched CNKI database for relevant literature, and a total of 111 articles were obtained. Famous scholars such as Sun Wei (2001; 2016), Jia Bing (2018; 2019) and Zeng Xiangbo (2018) have classified and analyzed the problems existing in Du Fu researches, the future development direction of Du Fu researches, and the inheritance and development of Du Fu spirit through international

$\begin{array}{lllll}\mathbf{K} & \text { C } & \text { AL-KINDI CENTER } \\ \mathbf{R} & \mathbf{D} & \text { FOR RESEARCH AN }\end{array}$ $\mathbf{R}$ D DEVELOPMENT Your gateway to world-class research

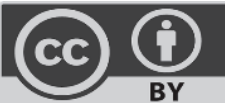

Published by Al-Kindi Center for Research and Development, London, United Kingdom. Copyright (c) the author(s). This open access article is distributed under a Creative Commons Attribution (CC-BY) 4.0 license 
academic seminars, symposiums, reading meetings, etc.; some scholars have classified and analyzed Du Fu research works of that year. This paper analyzes the research topics and hot trends within one year (Chen Na, 2018; Zhang Shuyi, 2019; Zhang Shaozhu, 2020); some scholars summarize the main achievements in recent decades by introducing the relationship between Du Fu and other fields such as Buddhism (Liu Wen, 2018). Domestic scholars have reviewed Du Fu researches from different perspectives and at different levels, but there is few literature that provides a comprehensive overview of relevant Western research results alone. With the development of digitization, the introduction of Du Fu research achievements and trends also ushered in the era of digital information. Therefore, this article will be based on Google Scholar database collates the relevant literature, and uses the bibliometric method and visual tool vosviewer to sort out the relevant papers, works and translations of Du's research in the West over the years, and analyzes the knowledge map of authors, institutional cooperation and research hotspots in relevant disciplines or fields, so as to explore the development trends, hot issues and research trends of Dufu research in the west, and provide a reference for the research. This paper makes a comprehensive review of the research and development of Du Fu in the West. In doing so, it will help to enrich the understanding of Western Du Fu research, provide a useful reference for the construction and development of Du Fu research, and provide some reference for Du Fu's academic research.

\section{Research methodology and data sources}

In this paper, the visualization method is used to analyze the knowledge map of Western literature in the field of Du Fu studies. The English literature mainly comes from the Google Scholar database.

\subsection{Research method}

The mapping of scientific knowledge depends on the combination of database and analysis software. In order to intuitively and concisely reflect the relevant information of Western Dufu research field, this paper uses vosviewer developed by Nees Jan van Eck as the analysis tool to draw the knowledge map of Western Dufu research field. The knowledge map drawn by vosviewer tool is intuitive and clear, and can avoid the influence of subjective factors. To a certain extent, it overcomes the shortcomings of traditional literature review.

\subsection{Data sources}

This paper uses publish or perish software to collect data from Google Scholar database. The citation analysis tool of publish or perish was released in October 2006 by Professor Anne-Wil Harzing of the University of Melbourne on the website (www.harzing.com/pop.htm). The most significant feature of pop software is its advantage, that is, its reference data comes from Google Scholar (GS), rather than Thomson ISI Web of Science (ISI) used in traditional cited research. In this study, the keyword "Du Fu Poetry" was used in the Google Scholar database, and a total of 999 articles were obtained. Unfortunately, there are only 43 English literatures published by western scholars through manual screening, and most of them are translated monographs. Compared with foreign countries, domestic research is far more abundant in content and research results. Although the development of Western Du Fu research has made great progress in recent years, it is still relatively slow.

\section{Discussion}

In order to grasp the development process and future trend of Du Fu research field as a whole, this paper systematically reviews the literature characteristics, research strength, research hotspots and frontiers in this field. This paper uses bibliometrics and visualization methods to understand the basic characteristics of the literature, summarizes the status of Western Du Fu research from the time of publication, publishing institutions and research power, and discusses the hot topics of overseas Du Fu research through keyword clustering.

\subsection{Date of issue and issuing body of English publication}

As an outstanding representative of poets in Tang Dynasty, Du Fu has already gone abroad and his influence has spread all over the world. According to incomplete statistics, there are at least 70 selected versions of Chinese poetry translated by foreign translators, including Du Fu poems, monographs of Du's poems and his collections with other famous poets (Wen Jun, 2013). This paper uses publish or perish software to collect data from Google Scholar database. It can be seen from the published years that the number of papers was flat from 1934 to 1992, and the number of papers was the highest from 1992 to 1996. In the $21 \mathrm{st}$ century, the study of Du Fu poetry in Britain and the United States was renewed, with a new surge from 2002 to 2006.

The translation and dissemination of Du Fu poems can not be separated from the medium of publication. To a great extent, the history of the publication of translated works also represents the history of their translation and dissemination. By examining the English translation and publication of Du Fu poems in Britain and the United States since the new century, we can objectively describe the trajectory of the translation and dissemination of Du Fu poems. According to the literature collected in this study, the study of Du Fu and Du Fu poems in the English world can be divided into three parts: translation, works and thesis. The following table shows the statistics of major foreign translations and monographs. 


\begin{tabular}{ccccccc}
\hline NO. & Type & Time & Press & Type & Time & Press \\
\hline 1 & Monographs & 1929 & London : Cape ; Boston : Houghton Mifflin & Translations & 1893 & Columbia University Press \\
2 & Monographs & 1934 & London : Cape & Translations & 1928 & Portland, Me., Mosher Press \\
3 & Monographs & 1967 & Oxford University Press & Translations & 1929 & Portland, Me., Mosher Press \\
4 & Monographs & 1971 & New York: Twayne Publishers & Translations & 1952 & degruyter.com \\
5 & Monographs & 1973 & Penguin Classics & Translations & 1988 & White Pine Press \\
6 & Monographs & 1989 & University Microfilms International & Translations & 1992 & HarperPerennial \\
7 & Monographs & 1992 & Faber and Faber & Translations & 1996 & W. W. Norton \& Company \\
8 & Monographs & 1992 & University of Hawaii Press & Translations & 2008 & Knopf \\
9 & Monographs & 2002 & Monumenta serica & Translations & 2009 & Everyman's Library \\
10 & Monographs & 2006 & Cambridge University Press & Translations & 2016 & DeGruyter Press \\
11 & Monographs & 2014 & Cork : BookBaby & & & \\
12 & Monographs & 2017 & brill & & & \\
13 & Monographs & 2018 & Critical Readings on Tang China & & & \\
14 & Monographs & 2020 & Hong Kong University Press & & &
\end{tabular}

\section{Figure1 Publication of major translations and monographs on western Du fu studies}

As can be seen from Figure 1, the main publishers of the monographs are divided into university press and social press. The main University Press include University of Hawaii Press, Columbia University Press, Cambridge University Press, Hong Kong University Press, etc. The main social publishers include Penguin Classics, Cape, Faber, cork, Brill, etc. Oxford University Press is the world's largest university press and also an academic press with a long history; Columbia University Press is one of the world's famous university press, ranking fourth among the oldest university press in the United States, publishing many books that were unique at that time and then became classics. Penguin Group is a subsidiary of Pearson PLC. It is one of the largest mass book publishers in the world. It is a symbol of high-quality novels and classic books. Its famous Penguin Classic Series has a farreaching influence on later generations. Cape in London is also one of the leading social publishers. These world-renowned publishers played an important role in the spread of Du Fu culture in the world.

The papers are published in a wide range of journals, the most popular and influential of which are Chinese Literature: Essays, articles, reviews (clear) and Tang studies. Chinese literature is an American academic journal in English. Founded in 1979, it is a pure academic English journal dedicated to the study of Chinese literature, with a wide range of contributions, a strong academic atmosphere, and high-quality articles, and is one of the representative journals of overseas Chinese literature research. For example, Charles Hartman, a famous sinologist, Daniel Hsieh of Purdue University, and Paul $f$ rouzer, a Sinologist of the University of Minnesota, have all published their papers in Chinese literature, which have received a high citation rate on Google Scholar. Tang studies is a purely academic journal focusing on the study of Tang Dynasty in China. It provides a platform for scholars from all over the world to exchange ideas and cooperate with each other in studying the history and figures of Tang Dynasty. In 2007, Stephen Owenan published some influential papers in Tang studies.

\subsection{The research power of Du Fu poems in the West}

"Du Fu's poetry represents the pinnacle of Chinese classical poetry art and realism tradition, which is not only well-known in China, but also highly respected in the English speaking world." (Li Tefu, 2012, p.89) Although the translation of Du Fu poems has a history of two or three hundred years, it was not until the last century that the monographs of Du poetry in English translation and monographs on Du Fu or Du poetry in English began to appear in the English-Speaking world. Figure 2 shows the important English translations and monographs collected on Google Scholar. Due to the relatively weak influence and the limited space available, this paper will not draw any more.

Statistics of Foreign Translations

\begin{tabular}{|c|c|c|c|}
\hline NO. & Authors & Translations & Time \\
\hline 1 & B Watson & The Selected Poems of Du Fu & 1893 \\
\hline 2 & $\begin{array}{c}\text { EW Underwood; } \\
\mathrm{CH} \text { Chu }\end{array}$ & The Book of Seven Songs by Tu Fu & 1928 \\
\hline 3 & $\begin{array}{c}\text { EW Underwood; } \\
\mathrm{CH} \text { Chu }\end{array}$ & Tu Fu: Wanderer and Minstrel under Moons of Cathay & 1929 \\
\hline 4 & W Hung & Tu Fu: China's Greatest Poet & 1952 \\
\hline 5 & S Hamill & Facing the Snow: Visions of Tu Fu & 1988 \\
\hline 6 & Vikram Seth & Three Chinese Poets: Translations of Poems by Wang Wei, Li Bai, and Du Fu & 1992 \\
\hline 7 & S Owen & An Anthology of Chinese Literature: Beginnings to 1911 & 1996 \\
\hline 8 & D Young & Du Fu: A Life in Poetry & 2008 \\
\hline 9 & P Harris & Three Hundred Tang Poems & 2009 \\
\hline 10 & S Owen, DX Warner, P Kroll & The Poetry of Du Fu & 2016 \\
\hline
\end{tabular}


Statistics of Foreign Monographs

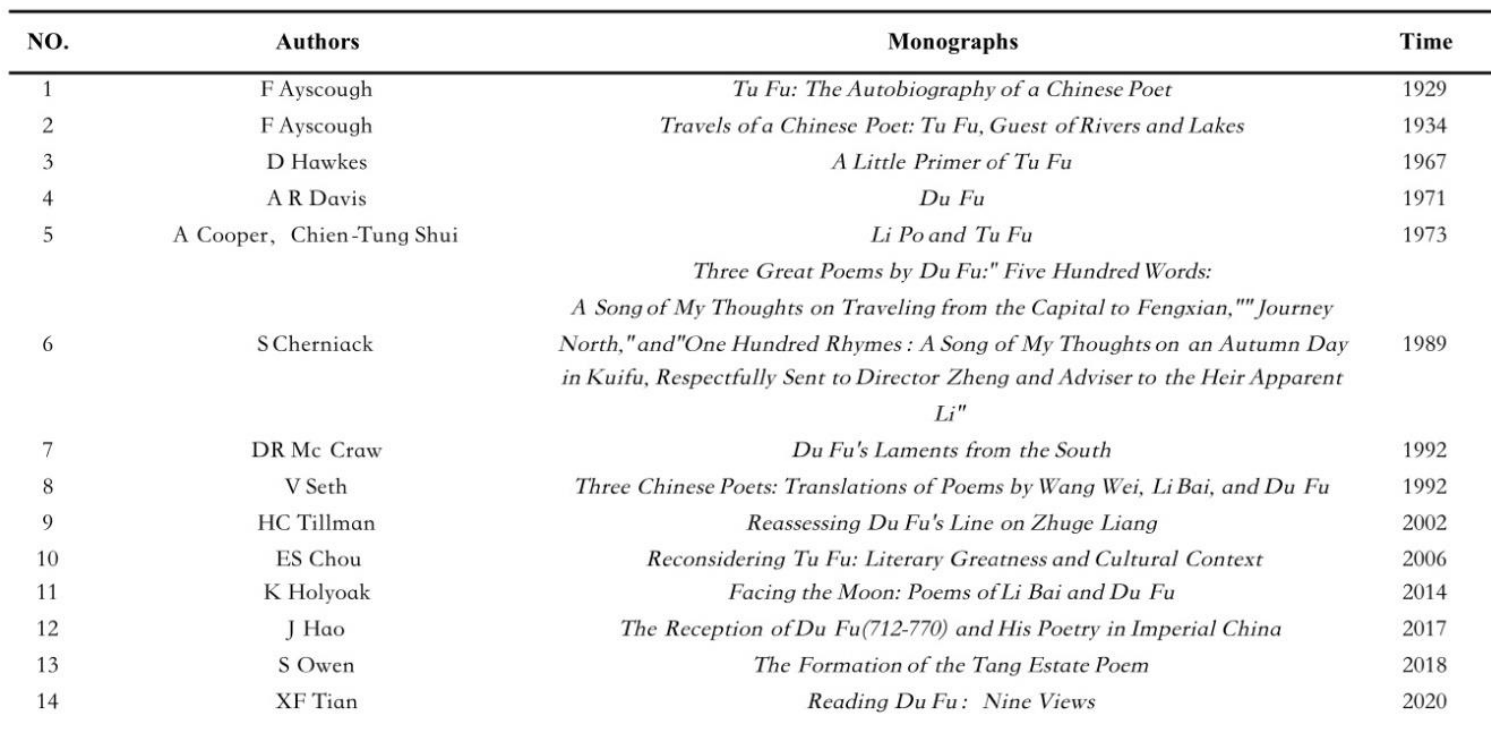

\section{Figure 2 The research power of modern Du Fu studies in the west}

The English translation of Du Fu poems first appeared in the book of Classic of Poetry published by James Legge in 1871, and continued to flourish until the 1950s, as can be seen from the dates of the publication of the translation in Figure 2. Among them, in 2016, Stephen Owen's publication "the poem of Du Fu",which took eight years to complete, was published including 1467 poems of Du Fu, making it the first complete translation of Du Fupoems and the first in the academic community. It should be noted that the translator has used footnotes and end notes to explain the high-frequency allusions in the appendix of each chapter in order to show the thousand poems to English readers as comprehensively as possible. In fact, as early as 1895 , Burton Watson, a famous sinologist in the United States, completed the selected poems of Du Fu, a special collection of Du Fu poems. (Li Tefu, 2015, p. 102). In 2008, David young, an American scholar and poet, published Du Fu: a life in poetry. The English translated poems selected in the book are closely related to Du Fu's life experience. Through the new arrangement of time and space, it comprehensively reviews the poet's life. According to the above chart, Edna Worthley Underwood is the only translator who has published two translations, namely, the book of seven songs by Tu Fu and Tu Fu: wanderer and minstrel under moons of Cathay. These two translations, both by the American poet and writer Underwood and the Chinese Chi-Hwang Chu, "established Underwood as one of the earliest translators of Du poetry in the English-speaking world (Li Tefu, 2012, p. 90)".Tu Fu: China's greatest poet was published by Harvard University Press in 1952 as a critical biography of Du Fu by William Hung, one of the first-class writers and critics of Du Fu. The book is arranged according to Du Fu's chronology, introduces and translates Du Fu and his works, which is an important document for the study of Du Fu poetry and English translation. Also worth mentioning is Murphy's Du Fu, written by American James R. Murphy. Although his works did not appear in our statistics as a general amateur poet, the author's great enthusiasm and contribution to Du Fu poetry are admirable, which also highlights the influence and charm of Du Fu poetry in the English world.

As the English translations of Du Fu poetry continue to develop, overseas works on Du Fu studies have gradually emerged. Among the English works cited in the Google Scholar database, the most highly cited is Arthur Cooper's "Li Po and Tu Fu" (1973) , a 249-page book, including several translated poems by Li Bai and Du Fu. The content also includes the introduction of Li Bai and Du Fu, the background of Tang Dynasty and the detailed translation methods. In 1992, the American scholar David R. McCraw's "Du Fu's laments from the south" was the second most cited monograph on Du Fu poems. McCraw translated poems with poems, and summarized the thoughts and language art of Du Fu poems in conclusion. In addition, American writer Florence Ayscough also deserves our attention. The first volume is entitled Tu Fu: The Autobiography of a Chinese poet, and the second volume is entitled travels of a Chinese poet: Tu Fu, guest of rivers and lakes. These two biographies of Du Fu are structured and compiled according to the chronological order of Du Fu. They focus on Du Fu himself rather than his poems. They tell the poet's own story through poems, which is the first time to "translate poems instead of biography" (Li, 2012). British Sinologist David Hawkes's "A little primer of Tu Fu" obviously takes a different route. This book focuses on Du Fu poems rather than his life. It integrates the introduction, research and translation of Du Fu poems, suggesting the poet's general life path through the creation time of his poems. In addition, Tu Fu (1971) by A. R. Davis is one of the most influential books in the English speaking world. It belongs to the Twas series, which specializes in the study of famous writers. 
The top three papers cited in English on google scholar are "Du Fu's gazing at the mountain" by Daniel Hsieh (1994) of Purdue University, and " the Tang poet Du Fu and the Song Dynasty Literati" by Charles Hartman (2008), both published in Chinese Literature: Essays, Articles, Reviews, one of the representative journals of overseas Chinese literature research. In addition, we also found that in 2007, the famous Sinologist Stephen Owen published an article entitled "a Tang version of Du Fu: the Tangshi leixuan" in the famous journal Tang studies. It is worth mentioning that in September 2020, the University of Hong Kong Press published the world's first collection of English papers on Du Fu, Reading Du Fu: Nine views, written by famous Chinese literature experts and young scholars. These essays, from a new perspective and under different backgrounds, give a detailed historical interpretation of Du Fu poems, including classic and little-known historical stories, and discuss a series of key issues. They are a collection of successful essays on the interpretation of Du Fu's complex images.

\subsection{Keyword clustering and research hotspots}

In this paper, the titles and abstracts of English literature, the titles and preface of translated monographs are selected and imported into Vos viewer software to make a knowledge map (Fig. 3), which examines the themes of overseas Du Fu studies according to keywords. It can be seen from the figure that overseas Du Fu research can be divided into six clusters, with a total of 42 entries. The main keywords of cluster 1 are cultural icon, image, interpretation; cluster 2 is Chinese political tradition, Li Bai, Wangwei; cluster 3 is Chinese literature, English, translation; Cluster 4 is complete poetry, criticalThe main keywords of cluster 5 are moon and subject; the main keywords of cluster 6 are poems and Tang poems. Through the statistical classification and analysis of the key terms, it is found that western scholars mainly focus on the translation and image understanding of Du Fu poetry, and also pay attention to other poets in the same period, such as Li Bai and Wang Wei, and make a comparative analysis.

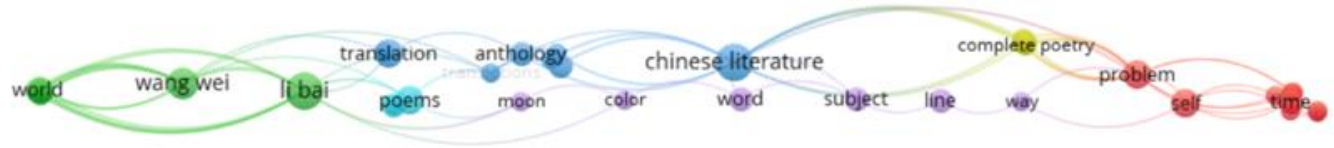

\section{Figure 3: keyword clustering diagram}

Therefore, based on a summary of the themes of Du Fu's overseas studies, this paper can be roughly divided into three research areas: the anthology of Tang poetry and the comparative study of Tang poetry; the translation strategies of Du Fu poetry; and the study of Du Fu poetry and image.

\section{1) Comparative study of ancient poetry anthology and poetry of Tang Dynasty poets}

In a search for studies related to $\mathrm{Du} F u$, it is found that western scholars began with the study of Tang poetry translation and then focused more on Du Fu poetry. In this process, scholars will make a comparative analysis of several famous poets and their poems in the same period. In 1996, Steve Owen published an anthology of Chinese Literature: beginnings to1911, which is known as a pioneering work in Chinese studies, collecting representative works from the 1000th year BC to the end of feudal society in chronological order, including texts of various schools, such as songs, letters, anecdotes, poems, etc. This innovative structure uniquely highlights the interaction among Chinese literature, culture and history. This book by Steve Owen is the most cited one among Google Scholar, which also opens the door for overseas scholars to study Chinese literature. In the Great Age of Chinese Poetry: the High T'ang not only defines the art of Chinese poetry in the eighth century through Wang Wei, Li Bai and Du Fu, but also deeply studies the norms of this era, understands the symbiotic relationship between the main talents and others in this era, as well as the whole literary tradition. Vikram Seth, an overseas Indian writer, is deeply attached to Chinese culture. In his translation of poems by Wang Wei, Li Bai, and Du Fu, Wang Wei, Li Bai, and Du Fu are regarded as the greatest poets in Tang Dynasty. He considers that Wang Wei is a "poetry Buddha", Li Bai is a "poetry immortal", and Du Fu is a "poetry saint". In their poems, they symbolize Buddhism, Taoism and Confucianism respectively. Therefore, Wang Wei was identified as a complative, Li Bai as a fantasist, and Du Fu as the social conscience of the times. In 1973, the world-famous Publishing House Peng classics published the American poet Arthur Cooper's translation of Li Po and Tu Fu: poems selected and translated with an introduction and notes, which is of far-reaching significance. In the book, the translator uses poetry as the carrier to analyze the images of the two poets. He believed that Li Bai and Du Fu were close friends and the greatest poets in China. Li Bai was a legendary reveler who completes his spiritual journey in the description of natural scenery and strong emotions. Du Fu balances Li Bai's pure escape and fantasy. In his autobiographical works, he shows the Confucian Humanity and the virtue of humility, simple and compassionate. The two poets of Tang Dynasty complement each other and are often called "Li Du". Their poems cover all aspects of life, experience and emotion.

\section{2) Study of the translation of Du's poems}

Google scholar has collected a large number of translations of Du poems, which are popular in the West and have been translated by many translators. Generally speaking, there are many translations of Du Fu's anthologies, and translators from 
different countries have their own merits in the selection and arrangement of Du Fu poems. The poem of Du Fu, written by Steve Owen, contains 1467 Fu poems, which is the first complete translation of Du Fu poems in the world. The selected poems of Du $\mathrm{Fu}$ is a collection of Du Fu poems written by Burton Watson, a famous American Sinologist, in the 19th century. There are 135 translations of Du Fu poems in the book. The translated poems are arranged according to the chronological order of the original poems. Keith holyoak, an American cognitive psychologist, learned about Du Fu poems through his translation and then began to translate them himself. His English translation of Du Fu poems is mainly found in facing the moon: Poems of Li Bai and Du Fu, with a total of 29 poems. The English translation of Du Fu poems by Jonathan Waley, a British scholar, is mainly found in spring in the broken city: Selected Poems of Du Fu, which contains 34 poems. The selected poems of Tu Fu, translated by David Hinton, an American scholar and poet, has more than 180 poems in total. Some of his later poems are included in his Chinese poetry translation, classic Chinese Poetry: an anthology, in which 30 poems account for a large proportion. It is found that western translators tend to adopt some domestication strategies in translating Du Fu poems. Due to the rhythmic features of Chinese classical poetry, foreign translators will give up the rhythmic features of the original poetry to adapt to the reading habits of English readers. At the same time, in the process of translation, translator's understanding of Du Fu poems is closely related to their understanding of Chinese culture, so some translators will add their own understanding to give new meaning to the poems, such as dealing with and annotating the prominent cultural allusions and images. In this process, there will be some cultural phenomena such as mistranslation and omission. The main spirit and cultural connotation retained and conveyed in the process of translating Du Fu poems have increased the readers' understanding and recognition, and promoted the spread and acceptance of traditional Chinese culture in the British and American world.

\section{3) Study of Du's poems and Images}

The first half of the twentieth century saw a climax in the study of Du Fu in the English speaking world, producing many monographs on Du Fu's life and poetry, such as Tu Fu: The Autobiography of a Chinese poet and a journey of a Chinese poet and Travels of a Chinese poet: Tu Fu, Guest of River and Lakes published by Florence Wheelock Ayscough in 1929 and 1934 respectively. This volume mainly covers Du Fu's experiences in his old age and illness from 759 to 770 . These two biographies are structured and written in the chronological order of Du Fu, focusing on his person rather than his poetry, telling the poet's own story through his poetry, pioneering the first "translation of poetry instead of biography". In 1952, Harvard University published William Hung's monograph Du Fu: the greatest poet of China. William Hung is an outstanding historian in modern China. He published the only English book in North America, which is a "biography of poetry" in a great sense.In this critical biography of $\mathrm{Du} \mathrm{Fu}, 374 \mathrm{Du}$ Fu's poems are quoted and translated. According to the chronological order of $\mathrm{Du} \mathrm{Fu}$, most of the poems are translated into English as the title or title of the chapter, describing Du Fu's life, explaining the background of his time and the significance of historical facts, and covering the main life course of Du Fu. David Hawkes, a famous British Sinologist, published his "the first stage of Du Fu's poetry"in 1967, which marks a new step in the research and introduction of Du Fu and his poetry in the English world. The book suggests the poet's general life path through the creation time of the poem. Dufu: life in poetry, written by David young, an American scholar and translator, is a collection of English translations of Du Fu poems, selected 170 poems related to his life experience, all of which are the manifestation of Du Fu's life course and reconstruct Du Fu's life in time and space.

\section{Conclusion}

By combining big data with visualization tools, this study takes the relevant English literature captured from Google Scholar database as the main research object, and uses the Publish or Perish tool, Excel datasheet and vosviewer to conduct the analysis of the volume of literature, authors of articles, research institutions, co-ciations, keyword clustering and other aspects. Visual analysis and knowledge mapping were carried out to analyze the current situation and research frontiers of Chinese and Western Du poetry, and the following conclusions were drawn on the latest situation of Du research in the West

(1) Although it has made great progress and attracted the cooperation of many world-famous publishers, its development is still relatively slow in terms of content and achievements. In recent decades, English translations of Western poetry have sprung up. First of all, the years of publication show that the number of articles published was flat from 1934 to 1992, and the number of published papers was the highest from 1992 to 1996. In the 21st century, the study of Du poetry in Britain and the United States has been renewed, culminating in another round of studies from 2002 to 2006. Secondly, an analysis of the major Western research forces and publishers on Du Fu reveals that such world-reowned publications as Oxford University Press, Columbia University Press, Penguin Classics University of Hawaii Press and other world-famous publishers have played an important role in the spread of Du Fu culture in the world. Famous academic journals such as Chinese literature and Tang studies also provide platforms for scholars from all over the world to exchange ideas and cooperate with each other in studying the history and characters of Tang Dynasty, which makes Du Fu culture more influential in the West. However, this study also found that western research began with the interpretation and translation of Tang poetry, and gradually focused on Du Fu's special research. Compared with domestic research, western studies are less rich in both content and research results than domestic research. Although progress has been made, it has been relatively slow. 
(2) There are limited but fruitful research topics and areas. This paper selects the titles and abstracts of English literature, the titles, introductions and prefaces of translated works, and imports them into vosviewer software for statistical analysis and classification.Western scholars mainly focused on the translation and imaginative understanding of Du Fu poems. They also focus on other poets of the same period, such as Li Bai and Wang Wei, and make a comparative analysis of them. In terms of themes, the study of Du Fu poems in the west can be divided into three main areas: comparative studies of the ancient poetry anthologies and the Tang Dynasty poets; the translation of Du Fu poems; and the study of Du Fu poems and images. The results of their research mainly focus on the English translation of Du Fu poems and the interpretation and evaluation of the poet's thoughts. This series of works enable western scholars to have a more detailed understanding of Du Fu poems and promote the globalization process of Du Fu poems. Not only has it contributed greatly $\backslash$ to the progress of Du Fu research, but also provides convenience for the overseas communication of Du Fu research.

(3)

(4) At present, the overseas research on Du Fu is still insufficient. First of all, the scope of research on Du poetry in English translation is too narrow. Most of the translations are anthologies of Du poetry, and the vast majority of Du poetry in English translation has not received much attention from researchers. Secondly, foreign studies on Du Fu poetry only regard it as an overall goal or result, that is, static research, but ignore the specific process of Du Fu poetry development, that is, dynamic research. Finally, due to cultural differences, there are still some obvious errors or omissions in the Western interpretation of Du Fu poems.

In addition to relying on the strength of domestic scholars, we should also make full use of overseas academic strength, which has not been given due attention in the past. This study aims to provide a comprehensive overview of the field of western Du Fu studies and to provide some reference significance for further study of Du Fu by providing a more objective picture of the development, thematic lineage and cutting-edge trends in modern western Du poetry studies.

Funding: This research was funded by Chinese Ministry of Education (ZP1823105) and East China University of Science and Technology (NO number exists.)

Acknowledgments: This paper would like to thank the following funding source: "Construction of Chinese Academic Translation Team Project" (ZP1823105) of the characteristic Humanities and Social Science Discipline Construction supported by Chinese Ministry of Education in 2018 and "2019-2020 Postgraduate Teaching Book Project Translation and International Communication" supported by East China University of Science and Technology.

Conflicts of Interest: The authors declare no conflict of interest.

\section{References}

[1] Chen Na. (2018). A Literature Review of Studies on Du Fu in 2017. Journal of Du Fu Studies, 02, 85-88.

[2] William, H. (2011). How I write about Du Fu. Shanghai Classics Publishing House.

[3] Li, T. (2012). The spread of Du Fu poetry in the English-speaking world: an analysis of major English translations of Du poems and English monographs in the English-speaking world in the 20th century. Journal of Du Fu Studies, 03, 89-94.

[4] Li, T. (2015). The translation and dissemination of Du Fu poetry in Britain and the United States in the 21st century: the first English translation of Du Poetry. Journal of Du Fu Studies, 03,100-104+125.

[5] Jia, B. (2019). Overview of the Second National Forum of Du Fu Cao Tang Museum in Chengdu. Journal of Du Fu Studies, 03, $122-125$.

[6] Jia, B. (2018). Overview of "the Symposium on Du Fu Studies in the Forty Years of Reform and Opening Up". Journal of Du Fu Studies, 03, 121123.

[7] Liu, W. (2018). A Summary of the Relationship between Du Fu and Buddhism. Journal of Du Fu Studies, 03, 28-36.

[8] Sun, W. (2001). An overview of the international symposium on Du Fu at the turn of the century. Literature Review, 01, 154-156.

[9] Sun Wei. (2016). Overview of the Symposium on Du Fu and Qilu Culture and the Second Academic Forum of Du Fu Reading Society. Journal of Du Fu Studies, 03,91-92+123.

[10] Wen, J. (2013). A study of the structure of Du Fu poetry in English translation. Foreign Languages and Their Teaching, 05, 61-64. doi:10.13458/j.cnki.flatt.003942.

[11] Zeng X. (2018). A review of the fifth Du Fu reading group. Journal of Du Fu Studies, 02, 89-91.

[12] Zhang, S. (2018). Overview of Du Fu Studies in 2018. Journal of Du Fu Studies, 01,120-124.

[13] Zhang, S. (2020). A review of Du Fu studies in 2019. Journal of Du Fu Studies, 01, 120-126. 